extremely difficult to create a successful environment. Families discontinued participation for a variety of reasons. If we can identify these reasons prospectively, we may be able to discourage some patients from beginning the intervention until potential barriers are resolved. It is desirable to delay participation of a family until there is a greater chance for success.

\section{CONCLUSIONS}

Pediatricians and their office staff were very interested in strategies to help identify and treat children who were overweight. Systematic identification of overweight children was easily introduced into the practice setting. Parents of young children ( 3 to 5 years old) who are overweight and of children at risk for over- weight infrequently recognize that their children are above the usual standards for weight. Accurate parental perception more often occurs in older children, in girls, and in children with the highest BMI. An in-office family-based intervention focused on behavior modification can be successful if barriers are identified and reduced.

To read or post commentaries in response to this article, see it online at http://www.annfammed.org/cgi/content/full/3/Suppl_2/S45.

Key words: Overweight; obesity; parents; child; pediatrics; primary care; nutrition; behavior modification; diet; physical activity

Submitted November 19, 2004; submitted, revised, February 9, 2005; accepted February 14, 2005.

Funding support: This project was supported by Prescription for Health, a national program of The Robert Wood Johnson Foundation with support from the Agency for Healthcare Research and Quality.

\title{
It Takes a Partnership: The Value of Collaboration in Developing and Promoting a Web Site for Primary Care Patients
}

\author{
Alex H. Krist, $M D_{i}{ }^{1,2}$ Steven H. Woolf, MD, MPH, ${ }_{i}{ }^{1,3}$ Stephen F. Rotbemich, MD, MS ${ }^{1}$ Robert E. Jobnson, PbD, ${ }^{1,4}$ \\ Diane B. Wilson, EdD, MS, RD \\ 'Department of Family Medicine, Virginia Commonwealth University, Fairfax, Va \\ ${ }^{2}$ Fairfax Family Practice Residency, Virginia Commonwealth University, Fairfax, Va \\ ${ }^{3}$ Department of Preventive Medicine and Community Health, Virginia Commonwealth University, Fairfax, Va \\ ${ }^{4}$ Department of Biostatistics, Virginia Commonwealth University, Fairfax, Va \\ ${ }^{5}$ Department of Medicine, Virginia Commonwealth University, Fairfax, Va \\ Ann Fam Med 2005;3(Suppl 2):S47-S49. DOI: 10.1370/afm.361.
}

Conflicts of interest: none reported

CORRESPONDING AUTHOR

Alex H. Krist, MD, 3825 Charles Stewart Dr, Fairfax, VA 22033, ahkrist@vcu.edu

\section{PURPOSE}

The purpose of our project was to develop a specialized Web site that helps patients pursue healthy eating, physical activity, smoking cessation, and moderation of alcohol consumption, and to integrate use of the Web site into primary care practice.

Encounters between patients and clinicians are a unique opportunity to promote healthy behaviors. Patients cite the advice of their physician as an important motivator for lifestyle change. ${ }^{1}$ Unfortunately, health care professionals are often ill-equipped to deliver the intensive counseling that is necessary to effect sustained behavior change. Among the various barriers-which include inadequate time, reimbursement, and counseling skills_-are the limitations most clinicians face in helping patients obtain the information they need for behavior change. ${ }^{2,3}$

To address these information needs, we worked with 6 primary care practices within the Virginia Ambulatory Care Outcomes Research Network (ACORN) to develop a Web site that patients could use at home to identify risky behaviors and enjoy convenient personal access to the best local and national resources on healthy behaviors. We aimed to both develop and evaluate the Web site within the 16-month grant period. The Web site's effectiveness was assessed with a pretest-posttest design, the results of which will 
be reported elsewhere. This article describes our experience in using a collaborative model to rapidly develop the Web site and promote its adoption.

\section{METHODS}

The My Healthy Living Web site ${ }^{4}$ differs from existing Web sites by combining 6 attributes: it is patient-centered, comprehensive, stage-tailored, evidence-based, user-friendly, and integrated into primary care. Firsttime Web site users answer a series of questions that assess health behaviors and stage of change. The Web site presents a portfolio of 200 local and national resources, tailored to individual health habits and readiness to change, which includes general information, tips, tools, resources for local support, information on special issues, and links for further assistance. It also provides individualized counseling messages and the option to print summary reports.

We used collaborative strategies to broaden input into the design of the Web site and to promote its implementation.

To develop our Web site, we sought input from 5 sources:

- Practices: The clinicians and staff who would later participate in the study were first engaged to help write the grant. Once the study was funded, we used existing office management infrastructures and 2 site visits at each practice to solicit input on the basic Web site concept, practice needs, perceived Web site value, study feasibility, and Web site promotional strategies. More than 90 physicians and 180 staff from the study sites gave input.

- The community: Four local partners assisted with identification of relevant community resources to post on the Web site. These partners comprised a local hospital system, a cancer center, a county park authority, and an alcohol treatment center.

- Experts: We engaged several behavioral scientists to help design the patient behavior questions and a framework to link resources with reported stage of change. A Web site programmer and database designer built the site's architecture. Graphics artists helped to make the Web pages attractive.

- Users: We beta-tested the Web site with mock users to identify problematic site features and to clarify the wording of questions.

- National organizations: We sought advice from 10 federal agencies, specialty societies, and voluntary health organizations. In telephone conferences and follow-up surveys, we asked these partners for input on study design, their organization's best resources to post on the Web site, and assistance in raising awareness about our project.
We had only 12 months for study enrollment and Web site assessment. We undertook 3 steps at the practices to ensure swift and sustained promotion of the Web site:

- Cementing practice buy-in: We conducted 2 site visits at each practice not only to obtain input, but also to foster clinician and staff acceptance of the Web site through an instilled sense of ownership. At each site, we identified 3 "champions" (a physician, a nurse, and an office manager) to promote the project and troubleshoot problems. We also e-mailed bimonthly newsletters to maintain study engagement.

- Promotional materials: Guided by advice we received from practices, we developed strategies to optimize patient awareness of the Web site. A graphic artist designed attractive posters to display prominently in lobbies and examination rooms. Tear-off pads on the posters enabled patients to bring the details home. Prescription pads containing similar information were distributed to clinicians. We mentioned the Web site on telephone hold line messages, health reminder fact sheets, and directions for obtaining laboratory test results. We prominently placed the Web site icon on each of the practices' Web sites. The practices took additional steps to promote the Web site: physicians and nurses personally recommended the site, and office managers ordered special stamps to add Web site information to standard patient mailings.

- In-service training: Approximately 1 month before the Web site was launched, we conducted a training session at each practice to provide a hands-on Web site demonstration and review the promotional materials that would be available.

\section{LESSONS LEARNED}

Our experience affirms the findings of others that a collaborative approach can be highly effective in designing and promoting quality improvement tools. ${ }^{5-10}$ Uptake of our Web site was immediate, and the rate of first-time patient visits persisted throughout the study period (Figure 1). Anecdotal reports from clinicians and patients were largely positive. Pending empirical data will determine whether the patients who could benefit visited the Web site in adequate numbers and whether the exposure was beneficial.

Web site users reported being directed to the site most frequently by their physician or nurse (reported by $38 \%$ and $8 \%$ of users, respectively). The enthusiasm of clinicians and staff in promoting the Web site, which the investigators observed directly, may reflect our efforts to engage them early in its development. These efforts cultivated clinician buy-in and Web site endorsement, and our efforts to familiarize them 


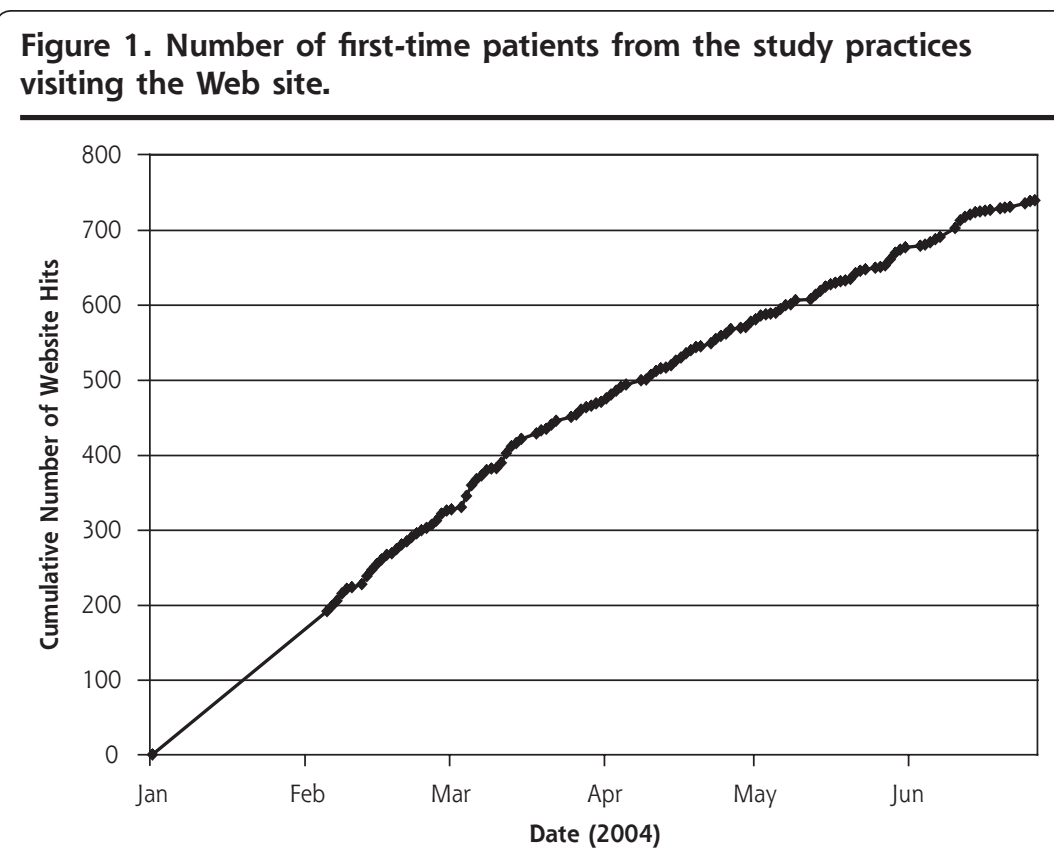

Note: The figure shows number of visits by first-time patients ( $y$-axis) over time ( $x$-axis) from the 6 study practices: visits by individuals who did not designate these practices as their primary source of care are not counted. The Web site was launched on January 5, 2004, and the patient enrollment period was January 5, 2004, through June 30, 2004. Active efforts to promote the Web site ceased in June, but the visit rate persisted thereafter.

and national partners, experts, and users. A collaborative model can leverage resources and helps achieve the best product to improve the quality of care.

To read or post commentaries in response to this article, see it online at http://www.annfammed.org/cgi/content/ full/3/Suppl_2/S47.

Key words: Internet; World Wide Web; practice-based research; primary care; health promotion/disease prevention

Submitted December 7, 2004; submitted, revised, February 17, 2005; accepted February 20, 2005.

Funding support: This project was supported by Prescription for Health, a national program of The Robert Wood Johnson Foundation with support from the Agency for Healthcare Research and Qualit

Acknowledgments: We would like to thank David Williams, PhD; Marshall Thompson; Greg Norman, PhD; Russell Glasgow, $\mathrm{PhD}$; the American College of Preventive Medicine; and Fairfax Family Practice Centers (Broadlands Family Practice, Herndon Family

with the content may have helped clinicians identify patients most likely to benefit. We conjecture, but cannot confirm, that the resulting clinician and staff enthusiasm accounted for a high level of patient interest in the Web site. Indirect evidence suggests the high level of interest: early in the study, patients had exhausted the supply of tear-off pads at most practices, forcing the practices to photocopy replacements.

The promotional materials that we developed also appeared to play an important role in Web site visits. Besides clinicians, wall posters and on-hold telephone messages were the leading means by which patients learned of the Web site (reported by $17 \%$ and $12 \%$ of users, respectively).

On a pragmatic level, we learned that a collaborative approach can produce a Web site with far less time and money than are normally required to field a product of this quality. Many who have complimented us on our Web site are unaware of the shoestring budget on which it was developed. Modest resources can be leveraged to achieve high quality by engaging talent and commitment through a multidisciplinary collaborative model.

\section{CONCLUSIONS}

We succeeded in designing and promoting a Web site in primary care practices through early and coordinated engagement of clinicians and staff, community
Medicine, Fairfax Family Practice, Prince William Family Medicine, Town Center Family Medicine, and Vienna Family Medicine).

\section{References}

1. Willms DG, Best JA, Wilson DM, et al. Patients' perspectives of a physician-delivered smoking cessation intervention. Am J Prev Med. 1991;7:95-100.

2. Mcllvain HE, Backer EL, Crabtree BF, Lacy N. Physician attitudes and the use of office-based activities for tobacco control. Fam Med. 2002;34:114-119.

3. Jaen CR, Mcllvain H, Pol L, Phillips RL Jr, Flocke S, Crabtree BF. Tailoring tobacco counseling to the competing demands in the clinical encounter. J Fam Pract. 2001;50:859-863.

4. My Healthy Living. Web site. Available at: http://www.myhealthyliving.net. Accessed October 2004.

5. Crabtree BF, Miller WL, Addison RB, Gilchrist V, Kuzel AJ. Exploring Collaborative Research in Primary Care. Thousand Oaks, Calif: Sage Publications; 1994.

6. Macaulay AC, Commanda LE, Freeman WL, et al. Participatory research maximises community and lay involvement. North American Primary Care Research Group. BMJ. 1999;319:774-778.

7. van Weel C, Rosser WW. Improving health care globally: a critical review of the necessity of family medicine research and recommendations to build research capacity. Ann Fam Med. 2004;2(Suppl 2):S5-S16.

8. Berg AO, Gordon MJ, Cherkin DC. Practice-Based Research in Family Medicine. Kansas City, Mo: American Academy of Family Physicians; 1986.

9. Lathlean J, le May A. Communities of practice: an opportunity for interagency working. J Clin Nurs. 2002;11:394-398.

10. Future of Family Medicine Project Leadership Committee. The future of family medicine: a collaborative project of the family medicine community. Ann Fam Med. 2004;2(Suppl 1):S3-S32. 